\title{
Field Training
}

\section{In Public Health}

\author{
An experimental program \\ of the School of Public Health,
} University of North Carolina

\author{
By EDWARD G. McGAVRAN, M.D., M.P.H., WILLIAM P. RICHARDSON, M.D., M.P.H., \\ GILBERT L. KELSO, M.P.H., and ALPHA K. KENNY
}

$\mathrm{T}$ HE GROWING RECOGNITION of the concept of the community as the patient of public health makes it increasingly evident that education in public health must involve, in much larger measure than heretofore, direct experience with this "patient" as an integral part of the academic school curriculum.

Public health techniques of epidemiological investigation, survey, and analysis can be likened to the diagnostic procedures and techniques developed by medical science for the individual patient over the past 50 years. The teaching of techniques and procedures can be best done, as has been acknowledged in most fields of professional education, by guided practice under close supervision-whether this be bedside teaching in medicine and nursing, chair-

Dr. McGavran is dean of the School of Public Health, University of North Carolina. Dr. Richardson, director of the department of field training of the School of Public Health until July 1, 1952, is professor of preventive medicine and assistant dean for continuation education of the university's School of-Medicine. Mr. Kelso is the department's sanitation consultant and since July 1, 1952, has been its director. Miss Kenny is educational director of public health records and statistics of the department. side teaching in dentistry, or practice teaching in education. Maintaining the medical analogy, field training becomes the "clinical" education in public health, providing for the public health student through practice in the community the equivalent of bedside practice for the medical student. The community is the bedside for education in public health.

Fifty years ago formal medical education was carried on largely in classroom and laboratory, with occasional observation of a patient in the amphitheater or operating room. Today, much of education in public health is at about that stage of development, with only occasional opportunity to observe the "patient" firsthand, and even less opportunity to develop diagnostic and therapeutic skills through guided practice.

Clinical education as an integral part of formal medical education was not arrived at quickly nor easily. Many objections and obstacles were placed in the way of providing the student with bedside clinical experience before he was graduated. The cost alone of such education was an almost insuperable obstacle. The lack of clinical instructors who were real teachers and responsible to the medical schools also delayed the development. But it has been accomplished in medicine, largely as a result of the leadership in medical education provided by the Association of American Medical Schools. 
During the past 5 years the School of Public Health at the University of North Carolina has attempted to develop one approach to the problem of "clinical" teaching of public health by emphasizing "community-side" experience.

With the aid of the W. K. Kellogg Foundation, the Training Branch of the Public Health Service Communicable Disease Center, and the North Carolina State Board of Health, a department of field training was set up as 1 of the 12 departments of the school in 1948. It was not conceived that this department alone could develop the resources and provide "clinical" education for all the disciplines of public health in the school, but rather that it might stimulate and aid the other departments of the school in developing and using the clinical edu. cational approach. Nor was it the purpose to conduct inservice training programs for the States, but rather to provide stimulation and assistance to States in developing the types of inservice training which could meet their particular needs.

Field training can logically be divided into two parts: (a) the "clinical," or "communityside," component of the complete professional education, a responsibility of the schools of public health with complete cooperation of the service agencies; $(b)$ inservice and continuation education, a responsibility of the service agencies (State and local health departments) with complete cooperation of the schools of public health.

\section{"Clinical" Education}

Prior to the establishment of the department of field training, only 2 departments of the School of Public Health-health education and public health nursing-had developed a planned and supervised "clinical" educational experience for their students. Today, 3 more departments-parasitology, nutrition, and biostatistics-routinely require planned and supervised field experience, and 3 others-sanitary engineering and sanitation, maternal and child health, and public health administration-provide planned and supervised field experience for certain of their students. This "clinical" education is part of the total academic program.
Full university credit is given and tuition and fees are charged.

Work for which university credit is given must, of course, meet high educational standards. The most important factor in obtaining a high standard in clinical education is provision of a good instructor-one who can make a good learning experience out of a work situation. The facilities, the health department's excellence, the health status of the community, are of secondary importance. We find that in the past overemphasis has been placed on demonstration centers and training centers as a prerequisite to clinical education. Extending the medical analogy, a student may learn more upon a "sick patient" than upon a "well patient" if he has a good instructor. By concentrating on the instructors, we have found that excellent clinical instruction can be given in a wide variety of health departments and communities. As many as 32 different health departments have been used in a single year, and those used are changed from year to year.

The following techniques have been used to insure high educational standards while at the same time providing the flexibility which will encourage the development of new and better approaches.

1. The tutorial system is followed at the "community-side," with a $1: 1$ ratio of student to instructor, occasionally a $2: 1$ ratio.

2. The field instructor is made to feel in every way that he or she is a member of the faculty of the School of Public Health. He is the "clinical professor." He is brought to the university before the student goes to the field and participates in a working conference where detailed plans for clinical instruction are developed.

3. The field instructor meets the student for whom he is to provide clinical instruction, discusses the student's needs and academic experience with both the student and the school's professors, and shares with other instructors the plan, the tools, and the techniques which he expects to use.

4. In the field, the student and the field instructor keep a report of their clinical experience which becomes a part of the curriculum of the next academic quarter for the student.

5. A faculty member of the school visits the 
local health department at least once while the student is there. At that time the student and instructor review problems and progress in the educational plan.

6. The field instructor receives a token honorarium from the school, as does the local supervisor and health department.

\section{Health Officers' Continuation Education}

The major activities in health officer training have been concerned with the residency program, which assumed importance with the promulgation of the certification requirements of the American Board of Preventive Medicine in 1948. The School of Public Health's department of field training has participated in a series of national conferences devoted to developing and establishing standards, criteria, organizational pattern, and program content. One of these conferences, sponsored by the school in cooperation with the W. K. Kellogg Foundation, was held in Chapel Hill, N. C., in December 1951, and was devoted largely to working out principles and details of the actual training experiences the resident was to receive (1).

The department staff developed, in cooperation with the North Carolina Advisory Committee on Training, a residency plan for North Carolina and prepared a handbook for the program. The plan has been approved by the Council on Medical Education and Hospitals, and the Board of Preventive Medicine, and accreditation given to centers in four local health departments: Orange-Person-ChathamLee District, Forsyth County unit of the Forsyth-Davie-Stokes-Yadkin District, Charlotte, and Halifax County. Five physicians have taken residency training under the North Carolina program.

A number of short institutes have been developed for local health officers on specific topics which they requested: communicable diseases, radiological health, health of the schoolage child, and others.

\section{Training for Sanitation Personnel}

Any sound and worthwhile program of inservice training must be developed within the administrative framework and operating pol- icies of the State concerned and must be consistent with the needs and readiness of the State for training activities.

To determine and define the objectives of inservice training for sanitation personnel, a conference was held in April 1950 at the School of Public Health with nationwide participation by training and administrative personnel from Federal, State, and local health agencies. This group formulated and published broad recommendations (2), variations of which have been found applicable to many situations by the University of North Carolina and the States. The problems of recruitment, job classification, and personnel turnover in sanitation are intimately associated with training problems. Several meetings of sanitary engineers from the southeastern States were held to consider these problems. A final report was developed, which has been valuable as a guide to job classification in several States (3).

Eleven 3-month general field training courses have been conducted for a total of 103 sanitarians in North Carolina, in which the department of field training and other departments of the School of Public Health, the North Carolina State Board of Health, and selected local health departments have cooperated. A total of 7 topical refresher courses each of 1 or 2 weeks' duration, in insect and rodent control, dairy sanitation, and food handling sanitation have been held to stimulate the professional growth and development of the sanitarians. At the request of the respective State departments of health, the department of field training has also assisted in stimulating and developing field training programs in sanitation in Maryland, Virginia, West Virginia, and South Carolina.

As a result of this department's activities and interstate conferences of training personnel, a basic pattern of 12 weeks' field training has been recommended and used successfully in West Virginia, Virginia, and North Carolina. The purpose of this training is to guide newly employed personnel into community health programs with a minimum expenditure of time and funds. Integrated with topical refresher courses, it stimulates continued professional growth and development. 


\section{Inservice Education for Nurses}

As one step toward determining needs and demands for field training of nurses, a regional conference of representatives from the divisions of local health service and bureaus of nursing of the State health departments in the southeastern States was held in April 1949. The conferees discussed the recruitment and training of public health nurses and set up some priorities with respect to field training needs in the region.

The most immediate need expressed by the North Carolina State Board of Health was for a 3-month training program, combining field training with some didactic instruction, for a group of nurses who were ineligible for admission to a school or department of public health because of graduation from small nursing schools. Such a program was developed, providing training for 20 nurses and utilizing 7 local health departments. The plan included 2 weeks of didactic instruction given at the School of Public Health by members of the department of field training staff with participation from other members of the school faculty, 1 week at the State board of health, and 8 weeks of carefully planned experience in selected local health departments.

A beginning was made in the development of an apprenticeship program for well-qualified nurses entering the field of public health for the first time. Policies adopted included: (a) clearance of applicants with the School of Public Health as to eligibility for admission before acceptance; $(b)$ evaluation of the apprentice at the end of 4 to 6 months of experience to determine interest in and suitability for advanced training in public health; and (c) acceptance by the school of the apprenticeship in lieu of the 3 months of required field experience, provided it covers a period of at least 9 months and suitable reports on the experience are made available to the school. The apprenticeship program was interrupted, when reduced training funds eliminated it from the budget of the State board of health.

Because the number of nurses being recruited into public health in North Carolina was considerably greater than the number for whom advanced training could be provided in the im- mediate future, another pressing task was the development of a program for a short introductory period of field training or orientation. Budgetary considerations prompted a decision that 5 weeks be the duration of this experience. Over a period of several months subcommittees composed of nurses from the State board of health, local health departments which participated in the training, and the School of Public Health worked on various aspects of the programs, including policies, relationships, objectives, application procedures, experience content, and methods for evaluating and reporting on the work of the trainee. Out of this process was developed a handbook which is now used by all participating departments.

Each year some 25 to 30 nurses receive this introductory field training. As many as 11 different local departments provide the training grounds for from 1 to 5 nurses at a time.

Following completion of the guide for this program, the committees developed a comparable outline for the 3-month field experience required of public health nursing students in the School of Public Health. Although this experience had been provided for a number of years, no systematic statement of policies, relationships, plan, and content had previously been developed.

\section{Recordkeeping and Reporting}

Public health records represent a neglected area of training programs. Although records and reports are recognized as essential tools for public health program planning, operation, and evaluation, as well as for teaching, progress in the revision of recording and reporting systems has not kept pace with improvement in the quality of service and expansion of programs. Nor has training in this phase of public health work been promoted as an inservice measure nor offered by the schools to any appreciable extent.

Previous lack of attention to records made it necessary to begin with basic work at the operational level by going into the health departments and demonstrating some of the possible methods of meeting needs. The simplification of service records, the development of a survey-type short course for clerical workers, 
and the preparation of guide materials are among the activities undertaken.

A project to revise and simplify service records was carried out at the Orange County unit of the Orange-Person-Chatham-Lee District Health Department, in Chapel Hill in 1950 and 1951 (4). This project not only provided a more satisfactory record system for the agency, but also demonstrated the value of group participation in the solution of problems involving the different disciplines. A report on the project, describing the method of development and incorporating copies of the forms and instructions for their use, constitutes a reference used in the seminars on records and office management. These seminars are conducted as a part of the program of study for public health administration and nursing students at the school. Interest in and promotion of better recordkeeping in the health departments to which the students return have come as direct results of the seminars.

Four 2-week courses have been arranged at the School of Public Health for a total of 65 secretaries from local health departments in North Carolina. The purposes of these short courses are to offer instruction to those already employed in clerical positions and to stimulate interest on the part of State and local public health officials in sponsoring suitable academic and inservice programs of study for records personnel. The program of instruction includes lectures on the history and development of public health; the organization and relationships of local, State, Federal, and other health agencies; the administration of service programs; and recordkeeping, office procedures, and elementary statistical methods. The instructors for these courses have included members of the faculties of the School of Public Health and the Woman's College of the University of North Carolina, the State health officer and program directors of the State board of health, and Public Health Service personnel.

Copies of the report on the simplified records project of the Orange County health unit, the training program for clerical personnel, and other guide materials developed and produced in cooperation with the North Carolina public health nurses have been shared with other States and countries. Requests for materials often come through students; sometimes they come from visitors for whom individual conferences are arranged with the staff of the department of field training to discuss the subject.

Experience of the past 4 years has indicated that the basic cause of the unsatisfactory record work is failure to provide sufficient personnel who have the qualifications necessary to fill advanced supervisory and consultative positions. A working conference was sponsored by the department of field training in October 1953 (5) to define the area of knowledge and skills involved and to study means of attracting suitable candidates for these positions and types of public health training programs needed to prepare them for such responsibilities. Representatives from 13 southern States, the Public Health Service, and the W. K. Kellogg Foundation participated in the conference. The conference recommended a committee to explore possible sources and means of offering a program of study directed toward meeting this need. A number of States are now making plans to start revising their record systems and to develop State training programs for records personnel.

\section{Principles of Field Training}

As a result of 5 years of experience in field training in public health, certain principles and conclusions have emerged. It was early found to be inadequate and undesirable to depend on a limited number of established field training or demonstration centers in the usual connotation of highly developed and specially staffed departments designed to provide for all the field training needs of the State. Such field training centers wear out rapidly under continued student load, and they are subject to changes in staff and other circumstances which frequently render them unusable for periods of time. A consideration of the actual needs and potential demands for field training leads to the conclusion that the ultimate meeting of these needs necessitates the use of many local health departments, and that the workers in those used should accept field training as a normal and an expected part of their professional tasks-just as they now accept infant hygiene, communicable disease control, sanitary supervision and others. 
Broadening the base of participation in this way creates the problem of developing a sound educational program in an agency whose primary objective and responsibility is service and whose personnel have little or no training or experience in education. This problem has been approached by use of the principle of cooperative joint planning in the development of specific training activities. State health department staff members and workers from local departments who serve as field instructors have participated with the faculty of the School of Public Health at every stage of planning, development, and evaluation of the programs. Not only has this cooperation brought the benefits of the wisdom and experience of the health department workers to the planning process, but it has also provided a means of stimulating their interest and given them an understanding of educational philosophy, principle, and techniques. Through this means it has been possible to provide field training experience of a high degree of excellence, using a large number of different health departments.

If community-side, or clinical, training in public health is to fulfill its purpose, it requires as careful planning of the curriculum content, schedule, and methodology as does academic education. Constant efforts have been directed to this end, and substantial progress has been made. Curriculum guides or handbooks have been completed and are being followed in many of the specific programs. Close supervision by an educational director, periodic group evaluation of program and experience by field instructors and supervisors, and the use of objective examinations at the beginning and end of the training period are some of the other techniques which have been used to develop high standards of educational excellence.

Another principle of paramount importance concerns the relationship of field training to other parts of the individual's training and experience. Except on an emergency basis for subprofessional workers, field training should never be used as the only training program or as a substitute for recognized academic training. Rather, it should be used to provide the supervised experience in the field application of public health principles which is such an essen- tial part of the total training program and which can be provided in no other way. It should be planned in the light of the other elements of training and experience which the workers for whom a particular program is planned have had or will have. An individual's total educational experience should be an integrated whole, with each part planned to complement every other part.

\section{School Responsibility}

One of the important objectives of these experiments in field training was to determine the contribution which a school of public health has to make to field training. The experience of the University of North Carolina School of Public Health has convinced us that not only does a school of public health have a contribution to make, but it also has a responsibility in this field. The advantages of active participation by the school have been many:

1. The facilities and faculties of the several departments are available for consultation and assistance, thus enriching the programs. For example, the psychiatrist on the school's faculty has participated in seminars on human relations for the various groups of public health workers, and members of the department of health education have conducted seminars and demonstrations on health educational methods and techniques.

2. State health departments have turned naturally to an educational institution for consultation in inservice training. As a result of this relationship it has been possible to apply knowledge and experience gained in one State or area to other States and areas, benefiting all the programs.

3. Close relationship with the Training Branch of the Communicable Disease Center has made it possible to utilize many of the very considerable resources of that agency in the development and evaluation of training programs and has enhanced opportunities for service to other States.

4. The school itself has benefited from close association with the operating problems of the health departments. It has helped to keep the faculty from acquiring the "ivory tower" complex. 
REFERENCES

(1) Nationwide Working Conference on Public Health Residency, December 3-5, 1951 : Report and recommendations. Chapel Hill, N. C., School of Public Health, University of North Carolina. Processed.

(2) Nationwide Working Conference on Sanitation Field Training, First, April 25-28, 1950 : Report and recommendations. Chapel Hill, N. C., School of Public Health, University of North Carolina. Processed.
(3) Conference of Sanitary Engineers of Southeastern States: Proposed classification plan for sanitation personnel in southeast region. Adopted June 17, 1951. Chapel Hill, N. C., School of Public Health, University of North Carolina. Processed.

(4) Kenny, A. K. : Simplifying local service records. Pub. Health Rep. 68: 1200-1205 (1953).

(5) Working Conference on Training of Public Health Records Personnel, October 5-8, 1953: Report. Chapel Hill, N. C., School of Public Health, University of North Carolina. Processed.

\section{each month in}

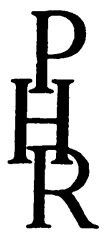

Technical ... scientific ... operational ... discussion papers on a wide range of subjects-health administration, disease control and epidemiology, environmental health and sanitation, health statistics, laboratory and technical reports, occupational health and industrial hygiene, international health operations-papers of direct value to administrators, physicians, dentists, engineers, nurses, educators, and other members of the public health practice and research teams ... plus notes on important scientific and governmental developments, and trends in morbidity and mortality, announcements of all new publications, films, and exhibits of the Public Health Service.

\section{for vour personal copy of}

use subscription blank on inside back cover

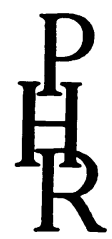

